\title{
Inhibition by Adrenomedullin of the Adrenergic Neurogenic Response in Canine Mesenteric Arteries
}

\author{
Tomio Okamura ${ }^{1}$, Jian-Xin Zhang ${ }^{1}$, Kenji Kangawa ${ }^{2}$ and Noboru Toda ${ }^{1}$ \\ 'Department of Pharmacology, Shiga University of Medical Science, Seta, Ohtsu 520-21, Japan \\ ${ }^{2}$ National Cardiovascular Center Research Institute, Fujishirodai, Suita, Osaka 565, Japan \\ Received January 16, 1997 Accepted February 7, 1997
}

\begin{abstract}
Adrenomedullin (AM) inhibited the pressor action caused by transmural electrical stimulation in perfused isolated canine mesenteric arteries. The inhibitory potency of AM was greater than that of calcitonin gene-related peptide (CGRP) or proadrenomedullin $\mathrm{NH}_{2}$-terminal 20 peptide (PAMP). [8-37]CGRP did not affect the inhibitory action of AM, but suppressed the CGRP-induced inhibition. It may be concluded that AM has an ability to inhibit adrenergic neuronal transmission without the mediation of $\mathrm{CGRP}_{1}$ receptors in the peripheral vasculature, and this inhibition partly participates in the potent hypotensive action of AM.
\end{abstract}

Keywords: Adrenomedullin, Adrenergic neurotransmission, Depressor action

Adrenomedullin (AM), a peptide originally isolated from human pheochromocytoma, possesses a potent hypotensive action. The AM action is reported to be derived from vasodilation because depressor action is associated with a decrease in total peripheral resistance in vivo (1), and marked vasorelaxation has been demonstrated in a variety of vascular preparations in vitro $(2,3)$. Because of its structural homology, the vascular action of AM has been compared with that of CGRP (calcitonin gene-related peptide), a potent endogenous vasodilator. Both compounds reportedly share the same receptor in canine central retinal (3) and rat mesenteric arteries (4). A radioligand study suggested the presence of AM-specific receptors (5). In contrast to the direct vascular action, the effect of AM on the perivascular nerve function has not been well-studied. The present study was conducted to evaluate the effect of AM on the adrenergic neuronal response in canine peripheral artery. The effects of proadrenomedullin $\mathrm{NH}_{2}$-terminal 20 peptide (PAMP), another novel hypotensive peptide contained together with AM in prepro-AM (6), and CGRP were also examined.

The Animal Care and Use Committee at Shiga University of Medical Science approved the use of canine blood vessels in this study. Thirteen mongrel dogs of either sex, weighing 7 to $13 \mathrm{~kg}$, were anesthetized with intravenous injections of sodium thiopental $(30 \mathrm{mg} / \mathrm{kg})$ and killed by bleeding from the carotid arteries. Proximal portions of the superior mesenteric artery, 0.9- to $5.0-\mathrm{mm}$ outside diameter, were isolated. The artery segment was placed in the bathing medium of 40-ml capacity and perfused luminally by modified Ringer-Locke solution maintained at $37 \pm 0.3^{\circ} \mathrm{C}$ and aerated with a mixture of $95 \% \mathrm{O}_{2}$ and $5 \%$ $\mathrm{CO}_{2}$ at a constant rate of $1 \mathrm{ml} / \mathrm{min}$ with a pressure of 40 to $50 \mathrm{mmHg}$ (7). Constituents of the solution were as follows: $120 \mathrm{mM} \mathrm{NaCl}, 5.5 \mathrm{mM} \mathrm{KCl}, 2.2 \mathrm{mM} \mathrm{CaCl}_{2}, 1.0$ $\mathrm{mM} \mathrm{MgCl}, 25.0 \mathrm{mM} \mathrm{NaHCO}$ and $5.6 \mathrm{mM}$ dextrose. The $\mathrm{pH}$ of the solution was 7.36 to 7.43 . The perfusion pressure was measured via a pressure transducer (NihonKohden Kogyo Co., Tokyo) placed upstream of the artery segment. Perfused segments were placed between a pair of stimulating electrodes each made of a platinum plate. The gap between the segment and the electrodes was wide enough to allow undisturbed contractions and yet sufficiently narrow to permit effective stimulation of intramural nerve terminals. Under resting conditions, electrical square pulses of supramaximal intensity $(10 \mathrm{~V}$, 0.2 -msec duration) were applied transmurally at frequencies of $5,10,20$ and $30 \mathrm{~Hz}$ for $40,20,10$ and $7 \mathrm{sec}$, respectively (total number of pulses, 200-210), every 10 to $15 \mathrm{~min}$ to stimulate perivascular nerves innervating the arterial wall. Transmural electrical stimulation was applied repeatedly until steady responses were obtained, and then the agents, AM, CGRP or PAMP, were directly applied to the bathing media. At the end, tetrodotoxin was applied to determine whether the induced response was 
due to stimulation of perivascular nerves. In preliminary experiments, the stimulation-induced increase in perfusion pressure was observed to be steady over a 2 -hr period.

The results shown in the text and figures are expressed as mean values \pm S.E.M. Statistical analyses were made by Student's unpaired $t$-test for two groups or Tukey's method after one-way analysis of variance for three groups. Human AM and PAMP were synthesized by the solid phase method and purified by reverse-phase HPLC (8). The other drugs used were human CGRP, [8-37]CGRP (Peptide Research Institute, Minoh), and tetrodotoxin (Sankyo Co., Tokyo).

In canine mesenteric artery segments perfused at a rate of $1 \mathrm{ml} / \mathrm{min}$, transmural electrical stimulation $(5-30 \mathrm{~Hz})$ produced a frequency-related increase in the perfusion pressure as seen in the previous study (7). At a frequency of $20 \mathrm{~Hz}$ applied at an interval of $10-15 \mathrm{~min}$, the pressor response was consistent and reproducible; therefore, the effect of various agents on the response to this frequency of stimulation was evaluated. The pressor response was abolished by treatment with prazosin $\left(10^{-5} \mathrm{M}\right)$ or tetrodotoxin $\left(3 \times 10^{-7} \mathrm{M}\right)$, suggesting the involvement of norepinephrine released by activation of perivascular adrenergic nerves.

AM $\left(10^{-10}-10^{-8} \mathrm{M}\right), \quad$ CGRP $\left(10^{-9}-10^{-8} \mathrm{M}\right)$ and PAMP $\left(10^{-9}-10^{-8} \mathrm{M}\right)$ significantly inhibited the pressor response to the transmural electrical stimulation in a dose-related manner (Fig. 1). The inhibitory effect of AM was significantly greater than that of CGRP or PAMP (Tukey's method) (Fig. 1). Treatment with $3 \times 10^{-7} \mathrm{M}$ [8-37]CGRP significantly reduced the inhibitory action of CGRP; mean inhibitory values with and without [8-37]CGRP treatment were $2.0 \pm 0.6 \%$ and $15.8 \pm 1.2 \%$ at $10^{-9} \mathrm{M}(\mathrm{P}<0.001, \mathrm{n}=5$, unpaired comparison) and $32.8 \pm 1.7 \%$ and $39.9 \pm 1.0 \%$ at $10^{-8} \mathrm{M}(\mathrm{P}<0.01, \mathrm{n}=5$, unpaired comparison), respectively. On the other hand, the AM-induced inhibition was not significantly affected by the CGRP analogue; mean inhibitory values with and without [8-37]CGRP treatment were, respectively, $10.8 \pm 0.2 \%$ and $10.8 \pm 0.3 \%$ at $10^{-10} \mathrm{M} ; 26.1 \pm 1.3 \%$ and $27.1 \pm 0.7 \%$ at $10^{-9} \mathrm{M}$; and $45.8 \pm 2.1 \%$ and $47.5 \pm 0.9 \%$ at $10^{-8} \mathrm{M},(\mathrm{n}=5)$. Typical recordings are illustrated in Fig. 2.

Pressor responses caused by transmural electrical stimulation in isolated perfused canine mesenteric artery segments were abolished by treatment with prazosin and tetrodotoxin. Therefore, the observed response is expected to derive mainly from norepinephrine released from electrically stimulated adrenergic nerve endings. The present study clearly demonstrates that AM significantly inhibited the pressor response to the electrical nerve stimulation, and the inhibition was not affected by treat-
CANINE PERFUSED MESENTERIC ARTERY SEGMENT

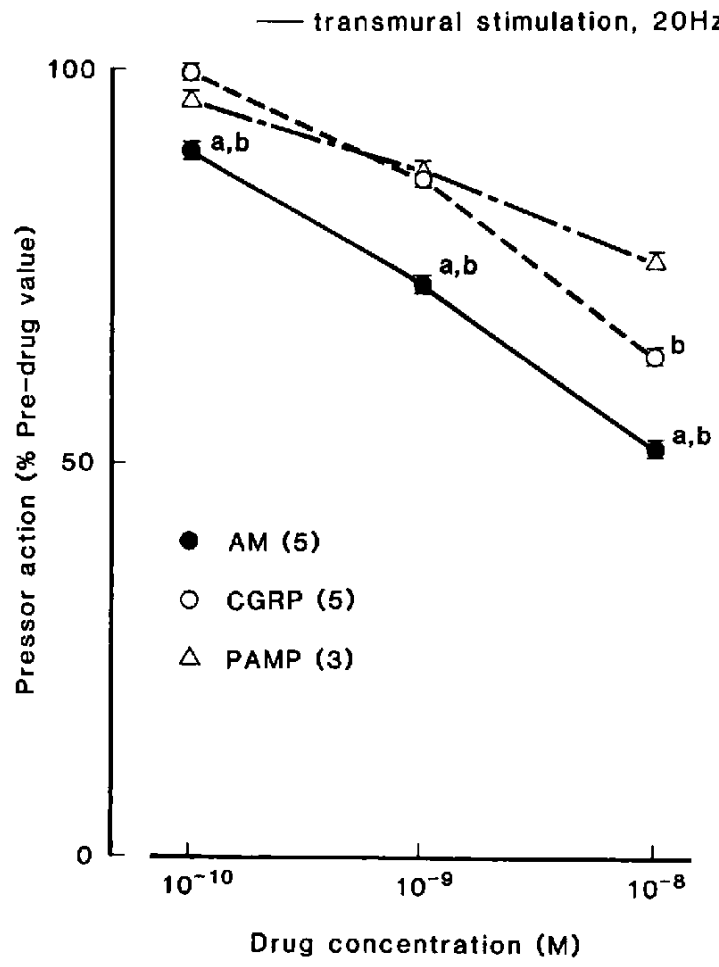

Fig. 1. Effects of adrenomedullin (AM), calcitonin gene-related peptide (CGRP) and proadrenomedullin $\mathrm{NH}_{2}$-terminal 20 peptide (PAMP) on the pressor action in response to transmural electrical stimulation $(20 \mathrm{~Hz}$ for $10 \mathrm{sec}$ ) in perfused isolated canine mesenteric arteries. Pressor actions were expressed as relative values to the perfusion pressure at the pre-drug period; the mean absolute value is

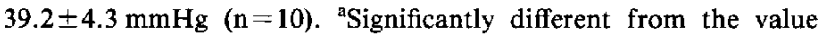
with $C G R P, P<0.01$; 'Significantly different from the value with PAMP, $P<0.01$ (Tukey's method).

ment with [8-37]CGRP at a concentration sufficient to suppress the CGRP-induced inhibition. These results suggest that AM has an ability to attenuate the function of adrenergic nerves innervating the peripheral artery, and receptors responsible for the inhibitory action of AM are distinct from those of CGRP. On the contrary, in our previous study with isolated canine retinal arteries (3), [8-37]CGRP markedly inhibited the endothelium-independent relaxations caused by both AM and CGRP, indicating that AM and CGRP shares the receptors located in the vascular smooth muscle and responsible for the relaxation in this artery. Similar results were obtained in canine mesenteric arteries (data not shown). Therefore, these data lead us to speculate that AM may inhibit the adrenergic neurotransmission prejunctionally through AM-specific receptors. The possible existence of AMspecific receptors has been reported in rat lung (9).

PAMP is another hypotensive peptide derived from proadrenomedullin (6). Shimosawa et al. (10) have 
CANINE MESENTERIC ARTERY SEGMENT — Transmural stimulation, 20Hz

Control
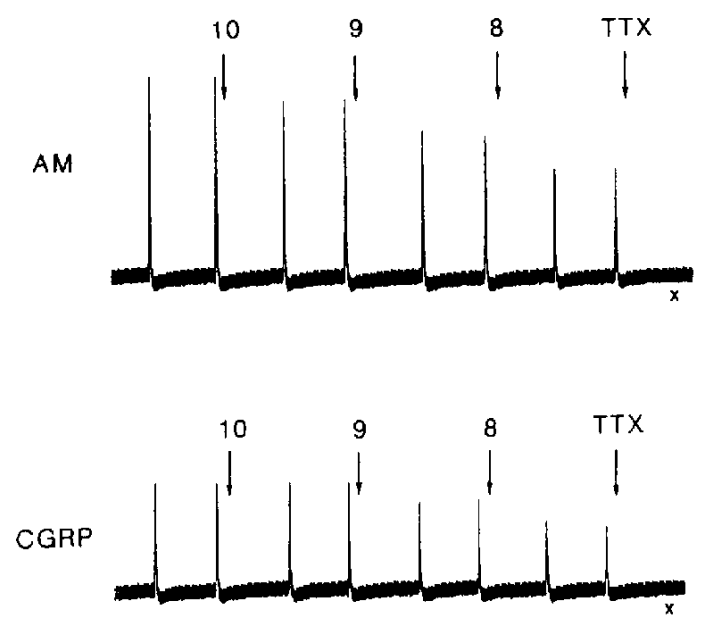

[8-37] CGRP-treated
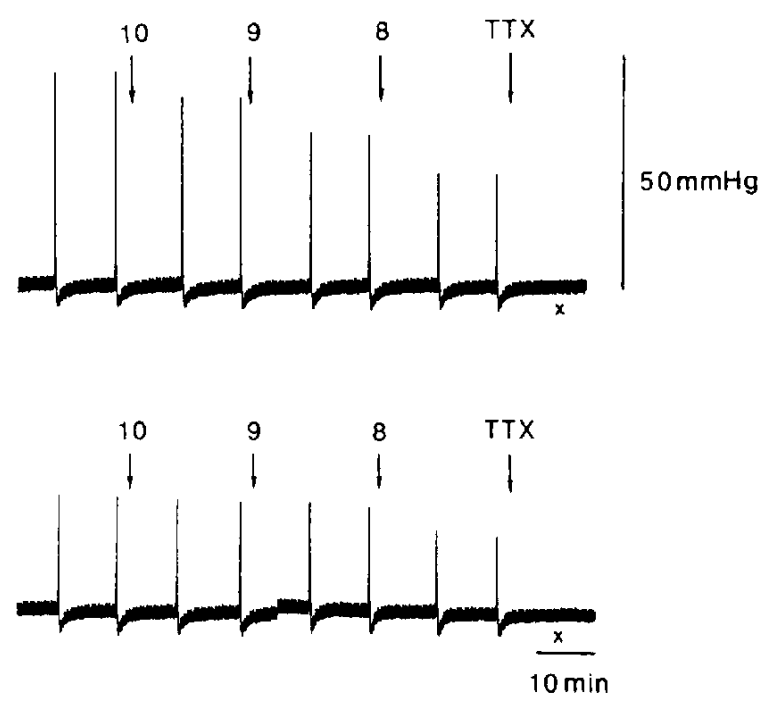

Fig. 2. Typical responses to transmural electrical stimulation $(20 \mathrm{~Hz}$ for $10 \mathrm{sec})$ of perfused mesenteric artery segments before and after treatment with adrenomedullin (AM, $10^{-10}-10^{-8} \mathrm{M}$, top tracings), calcitonin gene-related peptide (CGRP, $10^{-10}-$ $10^{-8} \mathrm{M}$, bottom) and tetrodotoxin (TTX, $\left.3 \times 10^{-7} \mathrm{M}\right)$ in the absence (left) and presence (right) of $[8-37] \mathrm{CGRP}\left(3 \times 10^{-7} \mathrm{M}\right)$. Drugs were cumulatively added directly to the organ bath. Numbers in the figure indicate the concentration of AM or CGRP in $-\log [\mathrm{M}]$. The " $\times$ " symbols below the tracings represent the application of electrical stimulation under treatment with TTX.

reported that PAMP, but not AM, inhibits noradrenaline overflow from peripheral sympathetic nerve endings in rat mesenteric arteries. On the other hand, the present findings show that AM exhibits a more potent sympathoinhibitory effect than PAMP in canine mesenteric arteries. Difference in the species of animals and the experimental methods including the condition of electrical stimulation used may be reasons for the discrepancy. The precise mechanism underlying the inhibition of sympathetic nerve function by AM remains to be clarified.

\section{REFERENCES}

1 Ishiyama $\mathrm{Y}$, Kitamura $\mathrm{K}$, Ichiki $\mathrm{Y}$, Nakamura S, Kida $\mathrm{O}$, Kangawa $K$ and Eto $T$ : Hemodynamic effects of a novel hypotensive peptide, human adrenomedullin, in rats. Eur J Pharmacol 241, 271-273 (1993)

2 Nakamura K, Toda H, Terasako K, Kakuyama M, Hatano Y, Mori $\mathrm{K}$ and Kangawa $\mathrm{K}$ : Vasodilative effect of adrenomedullin in isolated arteries of the dog. Jpn J Pharmacol 67, 259-262 (1995)

3 Okamura T, Ayajiki K, Kangawa K and Toda N: Mechanism of adrenomedullin-induced relaxation in isolated canine retinal arteries. Invest Ophthalmol Vis Sci 38, 56-61 (1997)

4 Nuki C, Kawasaki H, Kitamura K, Takenaga M, Kangawa K, Eto $T$ and Wada A: Vasodilator effect of adrenomedullin and calcitonin gene-related peptide receptors in rat mesenteric vascular beds. Biochem Biophys Res Commun 196, 245-251 (1993)

5 Eguchi S, Hirata Y, Kano H, Sato K, Watanabe Y, Watanabe TX, Nakajima K, Sakakibara S and Marumo F: Specific receptors for adrenomedullin in cultured rat vascular smooth muscle cells. FEBS Lett 340, 226-230 (1994)

6 Kitamura $\mathrm{K}$, Kangawa $\mathrm{K}$, Ishiyama $\mathrm{Y}$, Washimine $\mathrm{H}$, Ichiki $\mathrm{Y}$, Kawamoto M, Minamino N, Matsuo $\mathrm{H}$ and Eto T: Identification and hypotensive activity of proadrenomedullin N-terminal 20 peptide (PAMP). FEBS Lett 351, 35-37 (1994)

7 Zhang J-X, Okamura T and Toda N: Pre- and postjunctional modulation by endothelin-1 of the adrenergic neurogenic response in canine mesenteric arteries. Eur J Pharmacol 311, $169-176$ (1996)

8 Kitamura K, Kangawa K, Kawamoto M, Ichiki Y, Nakamura S, Matsuo $\mathrm{H}$ and Eto $\mathrm{T}$ : Adrenomedullin: a novel hypotensive peptide isolated from human pheochromocytoma. Biochem Biophys Res Commun 192, 553-560 (1993)

9 Kapas S, Catt KJ and Clark AJ: Cloning and expression of cDNA encoding a rat adrenomedullin receptor. J Biol Chem 270, 25344-25347 (1995)

10 Shimosawa T, Ito Y, Ando K, Kitamura K, Kangawa $\mathrm{K}$ and Fujita T: Proadrenomedullin NH(2)-terminal 20 peptide, a new product of the adrenomedullin gene, inhibits norepinephrine overflow from nerve endings. J Clin Invest 96, 1672-1676 (1995) 